O Open Access Full Text Article

\title{
Anti-tumor efficacy of folate modified PLGA-based nanoparticles for the co-delivery of drugs in ovarian
}

\section{cancer}

This article was published in the following Dove Press journal:

Drug Design, Development and Therapy

\section{Shu Li* \\ Xiaofeng Li* \\ Jianyi Ding \\ Lingfei Han \\ Xiaoqing Guo}

Shanghai First Maternity and Infant Hospital, Tongji University School of Medicine, Shanghai, People's Republic of China

*These authors contributed equally to this work
Correspondence: Xiaoqing Guo; Lingfei Han

Shanghai First Maternity and Infant Hospital, Tongji University School of Medicine, 2699 West Gaoke Road, Shanghai 201204, People's Republic of China

Tel +862120261000

Fax +862120261000

Email xiaoqing_guol00I@sina.com; lingfei_han2018@I63.com
Background: Ovarian cancer is a leading cause of death in gynecologic malignancies. The high mortality is mainly caused by advanced stage at presentation in most patients. Even after the combination of cytoreductive surgery and systemic platinum and taxane treatment, most patients relapse and eventually succumb to the disease. Therefore, there is an urgent need for new treatments.

Purpose: A novel folate (FA)-targeted co-delivery of docetaxel (DTX) and gemcitabine (GEM) nanoparticles (NPs) was developed to overcome ovarian cancer.

Materials and methods: Physicochemical characteristics of NPs such as size, morphology, and release profiles were explored. In vitro and in vivo studies were carried out to assess the efficacy of their antitumor activity in target cells.

Results: FA modified DTX and GEM co-loaded NPs were prepared using the solvent evaporation method. The NPs with a particle size of $\sim 120 \mathrm{~nm}$ were stable in the observation period. The hemolysis results indicated that FA-PEG 2000 -PLGA was potentially feasible for targeted antitumor drug delivery through blood circulation. In vitro release study suggested that in comparison with the free drug, PLGA-DTX/GEM NPs and FA-PEG ${ }_{2000}-$ PLGA-DTX/ GEM NPs had sustained-release properties. However, there was no obvious difference between the two NPs with the same drug in the release profile. Ovarian cancer cells in vitro efficiently took up the non-targeted and FA-targeted NPs; improved cytotoxicity was observed in the FA-targeted NPs, showing a 3.59- fold drop in the $\mathrm{IC}_{50}$ in SKOV-3 cells as compared to DTX/GEM alone. Cellular uptake showed that through surface modification, more drugs entered the cell successfully. Pharmacodynamics results showed a statistically significant effect on the rate of reduction of tumor volume for FA-PEG ${ }_{2000}-\mathrm{PLGA}-\mathrm{DTX} /$ GEM NPs than other groups and no toxicity of organs.

Conclusion: The present study indicates that the FA-PEG $2000-P L G A-D T X / G E M ~ N P s$ provides a promising platform for the treatment of ovarian cancer.

Keywords: folate, co-delivery, docetaxel, gemcitabine, nanoparticles

\section{Introduction}

Ovarian cancer is a leading cause of death in gynecologic malignancies. ${ }^{1}$ The high mortality is mainly caused by advanced stage at presentation in most patients. Even after the combination of cytoreductive surgery and systemic platinum and taxane treatment, most patients relapse and eventually succumb to the disease. ${ }^{2}$ Therefore, there is an urgent need for new treatments. Docetaxel (DTX) is a member of the taxane family. It has been shown to be effective for a variety of malignant tumors including ovarian cancer. ${ }^{3}$ 
However, the shortcomings of DTX, such as poor water solubility, low oral bioavailability and serious adverse reactions, have a negative impact on its clinical application. Side effects, including allergic reactions, fluid retention, neuromusculoskeletal toxicity and neutropenia, may be resulted from the fact that active pharmaceutical ingredients (API) or components of the solvent system need to dissolve hydrophobic DTX, such as Tween 80 or ethanol, which are associated with the formula of those currently in the market. Gemcitabine (GEM) is an S-phase-specific anti-metabolite with shown activity in a range of tumor types, especially those influencing the pancreas, lung and bladder. ${ }^{4}$

When GEM and other chemotherapeutic agents are used in combination, different modes of action lead to increased possibility of cytotoxic activity. In fact, in vivo experiments in murine tumors have shown the additive and super additive activity (mainly through the enhancement of induced apoptosis) when DTX and GEM are combined in different sequences. ${ }^{5}$ In addition, synergistic cytotoxicity has been reported in a human cancer cell line after administration of GEM followed by DTX $96 \mathrm{~h}$ later. $^{6}$ Some pharmaceutical experts have prepared DTX and GEM co-delivery preparation platforms, but unfortunately they are limited to the study of breast cancer. ${ }^{7-9}$

Folate receptor (FA) is a glycosylated phosphatidylinositol binding membrane glycoprotein widely distributed in normal and tumor tissues. $\alpha$ type folic acid receptor is the main subtype of folate transport, and is over expressed on the surface of various types of tumor, including pancreatic, prostate, lung, head and neck, breast and ovarian cancers, as well as mesothelioma. ${ }^{10,11}$ Over $90 \%$ of ovarian cancer cells overexpress folate receptors. ${ }^{12}$

Based on the above observations, we have studied the development of folic acid-targeted co-delivery PLGA nanoparticles of DTX and GEM (FA-PLGA-DTX/GEM NPs) in this study. The prepared NPs were characterized for drug loading and encapsulation efficiency, particle size, and surface morphology. Furthermore, the in vitro release profiles, cellular uptake and effect on cell viability in SKOV3 ovarian cancer cell lines of NPs were evaluated.

\section{Materials and methods Materials}

DTX and GEM were gifted by Hengrui Pharmaceuticals Co Ltd (Jiangsu, China). FA-PEG 2000 -PLGA or PLGA was purchased from Hunan Huaten Pharma (Changsha, China). SKOV3 ovarian cancer cell lines were purchased from the Shanghai Institute of Biochemistry and Cell Biology. The chemical and solvents used were analytical or HPLC. In this study, deionized water was used. Female Balb/c mice (5-6 weeks old, 25 \pm 2 g) were obtained from Laboratory Animal Center of Faculty of Pharmacy and Pharmaceutical Science, Tongji University School of Medicine, China. All animals were free from pathogens and had free access to food and water. Animal experiments were carried out in accordance with the guidelines issued by the National Institutes of Health and approved by the Tongji University School of Medicine.

\section{Preparation of FA-PEG 2000 -PLGA-DTX /GEM NPs}

FA modified DTX and GEM co-loaded NPs were prepared using the solvent evaporation method. Briefly, DTX (5 mg), GEM (5 mg) and FA-PEG 2000 -PLGA (100 mg) were dissolved in $10 \mathrm{~mL}$ of chloroform to produce oil phase. This was attached to a rotary evaporator and the organic phase was removed by evaporation at $45 \pm 2{ }^{\circ} \mathrm{C}$ to form a film on

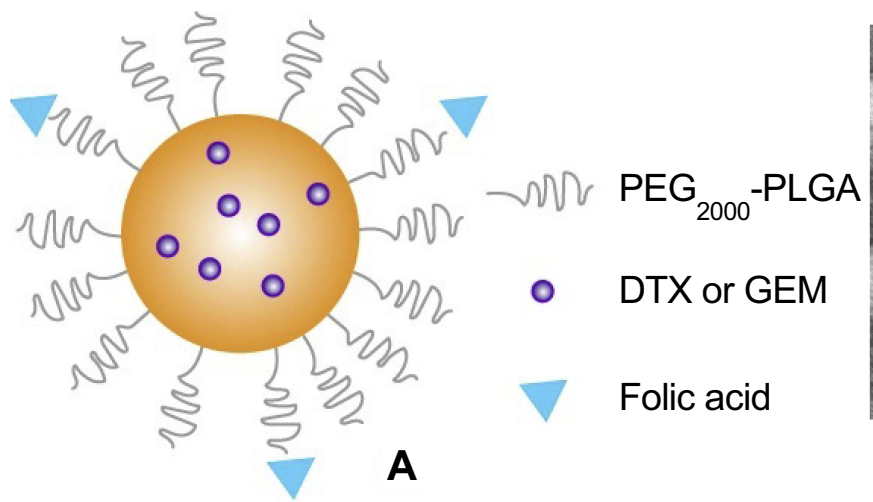

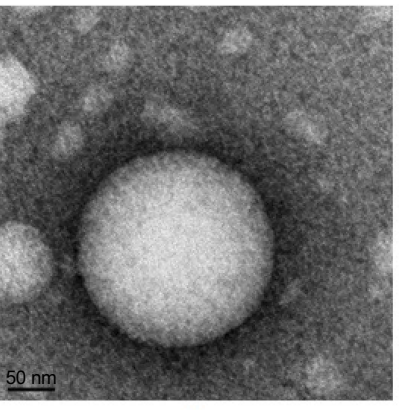

B

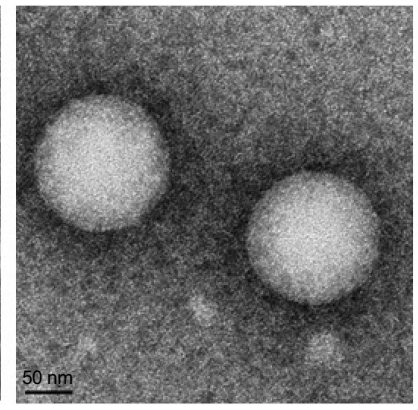

C

Figure I The microstructural schematic diagram of FA-PEG 2000 -PLGA-DTX/GEM NPs (A). Transmission electron microscope photograph of FA-PEG 2000 -PLGA-DTX/GEM NPs (B) and PLGA-DTX/GEM NPs (C). (amplification×44,000).

Abbreviations: DTX, docetaxel; GEM, gemcitabine; NPs, nanoparticles. 
the flask wall. The flask was kept overnight to remove any trace in the solvent. The lipid membranes were hydrated with $5 \mathrm{~mL}$ of phosphate-buffered saline (PBS, pH 7.4) at $37^{\circ} \mathrm{C}$ for 30 mins. After that, the suspension was mixed and homogenized for 10 cycles at 25,000 psi to obtain NPs preparations (Figure 1A). The suspensions in ultrafilter tubes $(\mathrm{MWCO}, 30,000 \mathrm{Da})$ were centrifuged at $1,000 \times \mathrm{g}$ for $30 \mathrm{~min}$ to remove free drug. Non-targeted preparations (PLGA-DTX/GEM NPs) without a folate conjugate and corresponding blank NPs without the DTX/GEM were prepared in a similar manner. The ultimate solution was filtered through a $0.8 \mu \mathrm{m}$ cellulose acetate filter unit, freeze-dried, and stored at $-20^{\circ} \mathrm{C}$ until use.

\section{Characterization}

Morphologies of NPs were observed by TEM (H-600; Hitachi, Tokyo, Japan) with an accelerating voltage of $75 \mathrm{kV}$. A droplet of copolymer solution $(0.5 \mathrm{mg} / \mathrm{mL})$ was deposited on a carbon-coated copper grid (200 meshes). A picture of the sample was taken after it was completely air-dried. Size distribution and zeta potential were determined by diluting $10 \mu \mathrm{l}$ of different NPs formulations in $10 \mathrm{ml}$ of deionized water and subjected to analysis using Zetas Sizer ZS (Malvern, Worcestershire, UK). The average size of each NPs formulation was determined by dynamic light scattering at room temperature and a fixed angle of $90^{\circ}$. The polydispersity index (PDI) of the droplets was determined for a count rate between 100-500 kcps. For zeta potential measurements, the diluted sample was placed in an electrophoresis tank and the charge was recorded.

\section{Entrapment efficiency and drug loading} Lyophilized powder of FA-PEG 2000 -PLGA-DTX/GEM NPs was dispersed in an aqueous medium containing $0.5 \%(\mathrm{w} / \mathrm{v})$ Tween-80 to dissolve DTX and GEM. After centrifugation at $14,000 \mathrm{rpm}$ for 15 mins (Eppendorf Centrifuge 5430; Hamburg, Germany), the free drug was separated from NPs by an ultracentrifugal filter (cut-off $10,000 \mathrm{Da}$ ). The amount of free drug was determined by HPLC. The entrapment efficiency and drug loading were calculated as follows:

$$
\text { Entrapment efficiency } \%=\mathrm{M}_{\text {drug }} / \mathrm{M}_{\text {added }} \times 100 \%
$$

$$
\text { Drug loading } \%=\mathrm{M}_{\text {drug }} /\left(\mathrm{M}_{\text {drug }}+\mathrm{M}_{\text {polymer }}\right) \times 100 \%
$$

where $\mathrm{M}_{\mathrm{drug}}$ is the mass of drug loaded in nanoparticles, $\mathrm{M}_{\text {polymer }}$ the mass of polymer in formulations, and $\mathrm{M}_{\text {added }}$ the mass of added drug.

\section{Stability study}

The accelerated stability study was conducted according to the International Coordinating Committee (ICH) guidelines (1993). The freshly prepared freeze-dried NPs were placed in a stable chamber at $25{ }^{\circ} \mathrm{C}, 60 \% \mathrm{RH}$. The NPs subjected to stability tests were analyzed over a 3-month period for physical appearance, size, physical and chemical properties and with a sampling frequency of 1 month.

\section{Hemolytic activity testing}

Hemolytic activity was evaluated by determining hemoglobin release from erythrocyte after incubation with different DTX/GEM NPs preparations. Simply put, blood from the rabbit ear artery was collected into tubes containing $124 \mathrm{mM}$ sodium citrate (sodium citrate: blood =1: 9, v/ v), centrifuged and washed with saline. The obtained red blood cells (RBC, $1 \mathrm{~mL}$ ) were diluted with saline to $10 \mathrm{~mL}$. $0.5 \mathrm{~mL}$ of the RBC suspension was incubated with different concentration NPs (Final Concentration $=0.02,0.05,0.15 \mathrm{mg} / \mathrm{mL}$ ) at $37{ }^{\circ} \mathrm{C}$ with gentle shaking. After $1 \mathrm{hr}$, the samples were centrifuged for $5 \mathrm{~min}$ at $3000 \mathrm{rpm}$ and the absorbance (A) of the supernatant was determined by UV-vis spectrophotometry at $545 \mathrm{~nm} .0 .5 \mathrm{~mL}$ of the RBC suspension with $2 \mathrm{~mL}$ of saline ( $0 \%$ lysis) was prepared as a negative control while water was used as a positive control (100\% lysis). The positive absorbance value should be $0.8 \pm 0.3$, and the negative should be less than 0.03 . The hemolysis rate of the sample was calculated by the following equation:

Hemolytic $\operatorname{rate}(\%)=\left[\left(\mathrm{A}_{\mathrm{t}}-\mathrm{A}_{\mathrm{nc}}\right) /\left(\mathrm{A}_{\mathrm{pc}}-\mathrm{A}_{\mathrm{nc}}\right)\right] \times 100 \%$ Among them, $A_{t}$ represents absorbance value of test sample, $A_{n c}$ and $A_{p c}$ represent the absorption values of negative and positive control respectively.

\section{In vitro release profiles}

In vitro release of drug from the FA-PEG ${ }_{2000}$-PLGA-DTX /GEM NPs was studied in an aqueous PBS medium ( $\mathrm{pH}$ 7.4 , containing $0.5 \%$ Tween- $80(\mathrm{w} / \mathrm{v})$ ). Briefly, an aliquot of NPs, containing a fixed amount of DTX or GEM $(10 \mathrm{mg})$, was introduced into a dialysis bag and then placed in PBS adjusted at $37{ }^{\circ} \mathrm{C}$ under gentle magnetic stirring $(75 \mathrm{rpm})$ in a volume of $200 \mathrm{ml}$ to achieve the sink condition. Drug release from different NPs went on for $24 \mathrm{hrs}$, and $1 \mathrm{ml}$ samples were withdrawn at predetermined time intervals and replaced with fresh medium. The concentrations of DTX or GEM in samples were analyzed by HPLC. The 
whole process of the experiment was performed in triplicate. The release of free drugs and PLGA-DTX/GEM NPs was also carried out in the same way as the control samples.

\section{Cytotoxicity assay}

The cytotoxicity of blank NPs, free DTX/GEM, PLGADTX/GEM NPs, and FA-PEG2000-PLGA-DTX/GEM NPs was evaluated by MTT assay in SKOV-3 cells. Briefly, the cells were maintained in RPMI 1640 culture medium supplemented with $10 \%$ FBS and $1 \%$ penicillin $(100 \mathrm{IU} / \mathrm{mL})$-streptomicin $(100 \mu \mathrm{g} / \mathrm{mL})$ under an incubation condition of $98 \%$ relative humidity and $5 \% \mathrm{CO}_{2}$. Each cell line contained $6 \times 10^{4}$ cells $/ \mathrm{mL}$, and was seeded in 96-well cell culture plates and incubated for $24 \mathrm{hrs}$ to ensure cell attachment under the above condition. Subsequently, the cells were treated with different samples: blank NPs, free DTX/GEM, PLGA-DTX/GEM NPs, and FA-PEG2000PLGA-DTX/GEM NPs. Each sample was prepared with a different DTX/GEM concentration (ranging from $5.0 \mathrm{ng} /$ $\mathrm{mL}$ to $1000 \mathrm{ng} / \mathrm{mL}$, and plates were incubated for $24 \mathrm{hrs}$, DTX:GEM=1:1). Cells were then incubated with $20 \mu \mathrm{L}$ MTT solution (5 $\mathrm{mg} / \mathrm{mL}$ in PBS) for $4 \mathrm{~h}$ before the medium was removed, and $200 \mu \mathrm{L}$ DMSO was used to dissolve cells. The absorbance was 570 and $490 \mathrm{~nm}$ as shown by the microplate reader (Thermo Fisher Scientific). The calculation formula of cell viability (\%) is as follows:

$$
\begin{aligned}
\text { Cell viability }(\%)= & \left(\mathrm{A}_{\text {Test }}-\mathrm{A}_{\text {Blank }}\right) /\left(\mathrm{A}_{\text {Control }}-\mathrm{A}_{\text {Blank }}\right) \\
& \times 100 \%
\end{aligned}
$$

$\mathrm{A}_{\text {Test }}, \mathrm{A}_{\text {Control}}$, and $\mathrm{A}_{\text {Blank }}$ represent the absorbances of the cells with different treatments, untreated cells, and blank culture media respectively. Each experiment was performed three times.

\section{Cellular uptake}

Cellular uptake of the FA-PEG2000-PLGA-DTX/GEM NPs was quantitatively compared to non-targeted NPs using coumarin 6 as a fluorescent probe, which was entrapped instead of DTX/GEM in the NPs. ${ }^{17}$ Briefly, SKOV-3 cells were placed in a 12-well plate at a density of $2 \times 10^{5}$ cells per well. After $24 \mathrm{~h}$ of incubation, coumarin 6-loaded FA-PEG2000-PLGA NPs, coumarin 6-loaded PLGA NPs and free coumarin 6, with the same final coumarin- 6 concentration of $0.5 \mu \mathrm{g} / \mathrm{mL}$ and diluted in culture medium, were applied to each well and incubated for a further $2 \mathrm{hrs}$. Then, cells were collected using trypsin-EDTA mixture $(0.25 \%-0.01 \%)$, washed twice with PBS, and centrifuged at $1,800 \mathrm{rpm}$ to remove any non-internalized particles. Finally, the cells were resuspended in PBS for flow-cytometry measurement using FACS Calibur (Becton Dickinson, Franklin Lakes, NJ, USA). In order to confirm that the fluorescence detected in flow-cytometry studies was resulted from the uptake of FA-PEG2000-PLGA-DTX/GEM NPs into the cells, free coumarin 6 was removed using dialysis bag (cutoff 12,000 Da).

\section{Antitumor study}

In the study of cancer treatment, each nude mouse was implanted with SKOV-3 cells $\left(5 \times 10^{6}\right.$ per mouse). When the initial average size of tumor reached $50 \sim 100 \mathrm{~mm}^{3}$, the mice were randomly divided into four groups $(\mathrm{n}=6)$ : the control group (PBS), free DTX/GEM, PLGA-DTX/GEM NPs and FA-PEG 2000 -PLGA-DTX/GEM NPs. Then the mice were given a dose of $10 \mathrm{mg} / \mathrm{kg}$ via the tail vein every 2 days for 3 weeks. The umor size and the body weight were examined and recorded every 3 days. The volume of the tumor $(\mathrm{V})$ was calculated according to the following formula: ${ }^{18}$ Tumor volume $\mathrm{mm}=$ Long diameter $\times$ Short diameter $^{2} \times 0.52$. After treatment, the mice were sacrificed. The main organs and tumors were weighed and the tissue sections were collected. The specimens were fixed with $4 \%$ paraformaldehyde and then paraffin embedded for hematoxylin and eosin (H-E) staining and histological examination.

\section{Statistical analysis}

Student's $t$-test was used to compare the two groups. $P<0.05$ was considered statistically significant. All data from the three independent experiments were expressed as the mean $\pm \mathrm{SD}$.

\section{Result and discussion Characterization}

The morphology of NPs was observed visually by TEM. FA-PEG ${ }_{2000}$-PLGA-DTX/GEM NPs could be selfassembled into spherical NPs with a diameter of $\sim 120 \mathrm{~nm}$ (Figure 1B). In contrast, PLGA-DTX/GEM NPs showed spherical morphology with a diameter of $\sim 110 \mathrm{~nm}$ (Figure 1C). The surface potential of two NPs was $-22.3 \pm 1.4 \mathrm{mV}$ and $-19.5 \pm 1.2 \mathrm{mV}$ respectively. Interestingly, the slight increase in the diameter of FA$\mathrm{PEG}_{2000}$-PLGA-DTX/GEM NPs and the slight reduction of PLGA-DTX/GEM NPs surface potential (absolute value) might be attributed to the hydrophilic ability and the surface charge-shielding effects of hydrophilic PEG 
Table I Characterization and stability study of the FA-PEG $2000-P L G A-D T X / G E M ~ N P s$ and PLGA-DTX/GEM NPs. ( $n=3$; mean \pm SD)

\begin{tabular}{|c|c|c|c|c|c|c|c|c|}
\hline \multirow[t]{2}{*}{ Formulation } & \multirow{2}{*}{$\begin{array}{l}\text { Time } \\
(\mathrm{m})\end{array}$} & \multirow{2}{*}{$\begin{array}{l}\text { Mean diameter } \\
(\mathrm{nm})\end{array}$} & \multirow[t]{2}{*}{ PDI } & \multirow{2}{*}{$\begin{array}{l}\text { Zeta potential } \\
(\mathrm{mV})\end{array}$} & \multicolumn{2}{|l|}{ DTX } & \multicolumn{2}{|l|}{ GEM } \\
\hline & & & & & DL\% & ER\% & DL\% & ER\% \\
\hline FA-PEG 2000 -PLGA-DTX/GEM & 0 & $123.7 \pm 8.32$ & $<0.14$ & $-22.3 \pm 1.4$ & $6.9 \pm 1.6$ & $81.3 \pm 3.3$ & $7.2 \pm 1.3$ & $77.7 \pm 6.8$ \\
\hline \multirow[t]{3}{*}{ NPs } & 1 & $123.8 \pm 7.45$ & $<0.17$ & $-21.9 \pm 1.3$ & $6.8 \pm 1.3$ & $82.6 \pm 4.7$ & $7.3 \pm 1.8$ & $76.9 \pm 6.5$ \\
\hline & 2 & $123.4 \pm 5.39$ & $<0.18$ & $-22.6 \pm 1.2$ & $6.6 \pm 1.4$ & $82.7 \pm 2.1$ & $6.9 \pm 1.1$ & $76.4 \pm 5.1$ \\
\hline & 3 & $124.2 \pm 9.45$ & $<0.19$ & $-21.1 \pm 1.6$ & $6.7 \pm 1.3$ & $81.9 \pm 2.5$ & $7.1 \pm 1.1$ & $75.9 \pm 4.9$ \\
\hline \multirow[t]{4}{*}{ PLGA-DTX/GEM NPs } & 0 & $118.5 \pm 8.29$ & $<0.19$ & $-19.5 \pm 1.2$ & $7.2 \pm 1.2$ & $84.9 \pm 6.4$ & $8.2 \pm 1.3$ & $82.5 \pm 7.1$ \\
\hline & I & $119.6 \pm 7.43$ & $<0.21$ & $-18.6 \pm 1.7$ & $7.3 \pm 1.3$ & $83.6 \pm 7.2$ & $8.1 \pm 1.7$ & $81.4 \pm 6.3$ \\
\hline & 2 & $|2| .8 \pm 8.52$ & $<0.23$ & $-18.4 \pm 1.3$ & $7.1 \pm 1.4$ & $82.8 \pm 5.9$ & $7.9 \pm 1.4$ & $81.3 \pm 4.7$ \\
\hline & 3 & $122.3 \pm 9.19$ & $<0.26$ & $-19.9 \pm 1.6$ & $7.2 \pm 1.3$ & $82.2 \pm 6.3$ & $7.8 \pm 1.5$ & $80.5 \pm 6.9$ \\
\hline
\end{tabular}

Abbreviations: PDI, polydispersity index; DTX, docetaxel; GEM, gemcitabine; NPs, nanoparticles.

outer layer. In the process of drug-delivery, physical coating and electrostatically interacted drug loading in carriers were expected to prevent premature drug loss. A favorable hydrodynamic diameter (around $100 \mathrm{~nm}$ ) ${ }^{13}$ and a negative surface charge ${ }^{14}$ were important in meeting the needs of advanced antitumor drug-delivery.

Drug entrapment efficiency (DTX) in FA-PEG $2000^{-}$ PLGA-DTX/GEM NPs was $81.3 \% \pm 3.3 \%$, slightly lower than the non-targeted PLGA-DTX/GEM NPs $(84.9 \%$ $\pm 6.4 \%$ ). Other parameters are shown in Table 1 .

\section{Stability study}

FA-PEG 2000 -PLGA-DTX/GEM NPs exhibited good stability during the three months. No significant changes in physical appearance or particle aggregation were observed. At the same time, NPs showed good physical stability. There was no obvious change in all the indexes during the observation period. No degradation was observed in DL\% and ER\% in the preparations (Table 1).

\section{Hemolytic activity testing}

Despite all these advantages in size and surface properties, intravenous injection of NPs always came with potential risks, such as causing severe erythrocyte damage known as hemolytic activity (lysis of red blood cells). Even excessive hemolysis activity could be seriously life-threatening. ${ }^{15,16}$ Therefore, the study of hemolytic activity is one of the important safety endeavors to prevent serious side effects in vivo. Although in practice, polymer concentration applied in blood is diluted, in order to ensure adequate safety, an excessively high polymer concentration in this study was examined.

Hemolytic images showed no obvious hemolysis in any polymer concentration (Figure 2). Although hemolysis increased slightly at a higher polymer concentration, that of PLGA-DTX/GEM NPs and FA-PEG 2000 -PLGA-DTX /GEM NPs was less than $5 \%$, which is considered to be non-toxic in in vivo applications. Low hemolysis indicated good biocompatibility and low toxicity even when the polymer concentration was as high as $0.15 \mathrm{mg} / \mathrm{ml}$. Therefore, the hemolysis results indicated that FA$\mathrm{PEG}_{2000}$-PLGA was potentially feasible for targeted antitumor drug delivery through blood circulation.

\section{In vitro release profiles}

The cumulative drug-release profile in vitro was shown in Figure 3. Over time, the release of DTX and GEM in NPs became much slower than that of free drug. Within $2 \mathrm{hrs}$, the cumulative release of free drug (DTX) was about $92 \%$ but only about $45 \%$ in NPs (GEM 82\%, 22\%). In this case, biphasic release was observed with DTX to be about $45 \%$ within $2 \mathrm{hrs}$, followed by a sustained release of about $77 \%$ within $24 \mathrm{hrs}$ (GEM 22\%, 60\%). The main reason for this phenomenon was that the drug loaded on the NPs was easier to release into the dissolution medium at first; that the NPs dissolved over time, and that the drugs within the particles were gradually released. It suggested that in comparison with the free drug, PLGA-DTX/GEM NPs and FA-PEG 2000 -PLGA-DTX/GEM NPs had better sustained-release properties. However, there was no obvious difference between the two NPs with the same drug in the release profile. After calculation, the in vitro drug-release kinetic model of DTX and GEM (FA-PEG 2000 -PLGADTX/GEM NPs) in release medium was found to fit well with the Higuchi equation: $Q=7.12 t 1 / 2-1.23$ (DTX, $\mathrm{r}=0.994)$ and $\mathrm{Q}=4.32 \mathrm{t} 1 / 2+0.32(\mathrm{GEM}, \mathrm{r}=0.993)$. Thus, it was speculated that the sustained-release properties of NPs could extend the absorption time of drugs in vivo. 

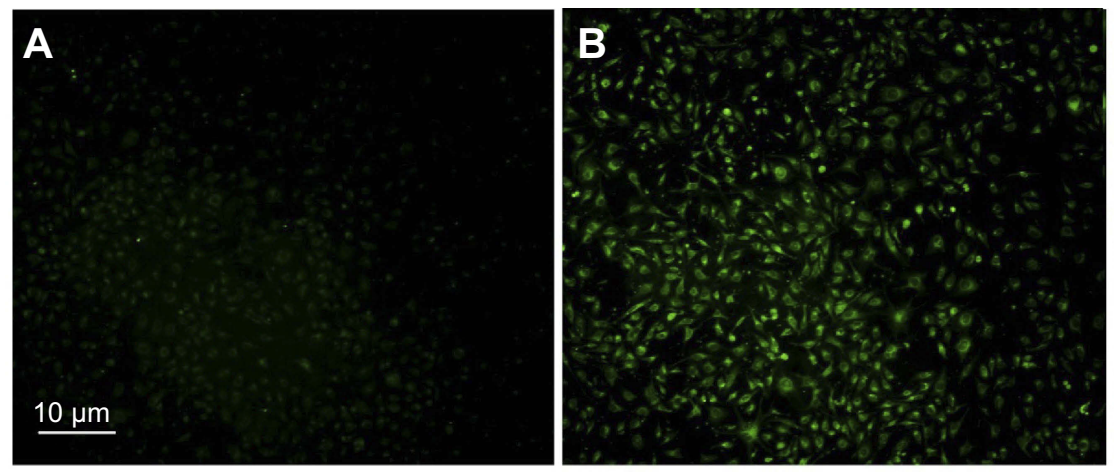

A

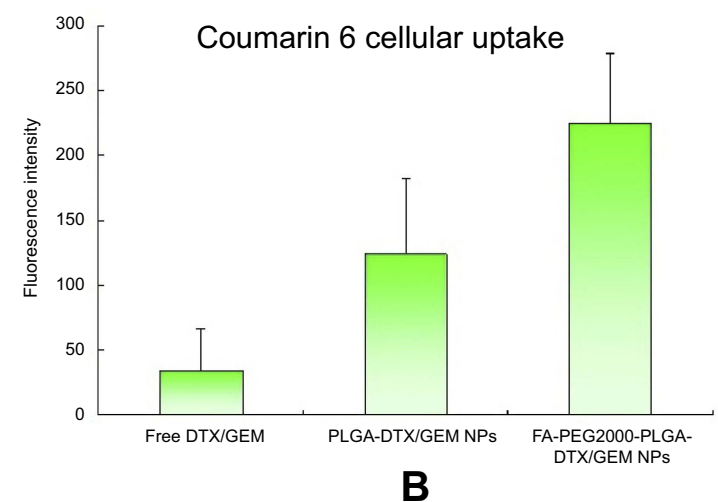

Figure 2 Hemolytic activity results (B) and photo images (A) at different polymeric concentrations.

\section{Cytotoxicity assay}

In order to investigate the in vitro cytotoxicity of FA-PEG 2000-PLGA-DTX/GEM NPs in comparison to free DTX/ GEM and PLGA-DTX/GEM NPs, MTT assay was performed on SKOV-3 cells. Blank NPs, which did not contain DTX/ GEM were used as controls. As shown in Figure 4, significant reductions in cell viability were observed in the FA-PEG2000PLGA-DTX/GEM NPs treated group, while the cytotoxicity of cells was clearly lower in the PLGA-DTX/GEM NPs treated and free DTX/GEM groups. In addition, blank NPs without DTX/GEM showed no apparent cytotoxicity to SKOV-3 cells, even at the highest concentration used $(1000 \mathrm{ng} / \mathrm{mL})$. According to the above results, although DTX and GEM were powerful antitumor drugs, they could not completely inhibit cell proliferation. Similarly, NPs conjugation of PTX/ CUR did not result in superior effect. The ability to suppress tumor cells was only slightly better than free DTX/GEM. According to the results obtained, FA-PEG2000-PLGA-DTX /GEM NPs treatment reduced cell survival more significantly compared with other groups.
The half-maximal inhibitory concentration $\left(\mathrm{IC}_{50}\right)$ values were measured by GraphPad Prism 5. Briefly, the $\mathrm{IC}_{50}$ value of the FA-PEG2000-PLGA-DTX/GEM NPs was $175.3 \mathrm{ng} / \mathrm{ml}$ compared with a value of $629.4 \mathrm{ng} / \mathrm{ml}$ for free DTX/GEM and $437.1 \mathrm{ng} / \mathrm{ml}$ for the nontargeted NPs, PLGA-DTX/GEM NPs.

\section{Cellular uptake}

Confocal microscopy was employed to characterize the cellular internalization of free coumarin 6, coumarin 6-loaded PLGA NPs and coumarin 6-loaded FA-PEG 2000-PLGA NPs in SKOV-3 cells. As shown in Figure $5 \mathrm{~A}$, a strong green fluorescence was observed in the cytoplasmic region of coumarin 6-loaded FA-PEG 2000-PLGA NPs after incubation for $2 \mathrm{~h}$. In SKOV-3 cells, the cell internalization of coumarin 6-loaded FAPEG2000-PLGA NPs was higher than others.

The results showed that more drugs entered the cell successfully through surface modification of NPs. In the study of quantitative cell uptake, through the recovery of 


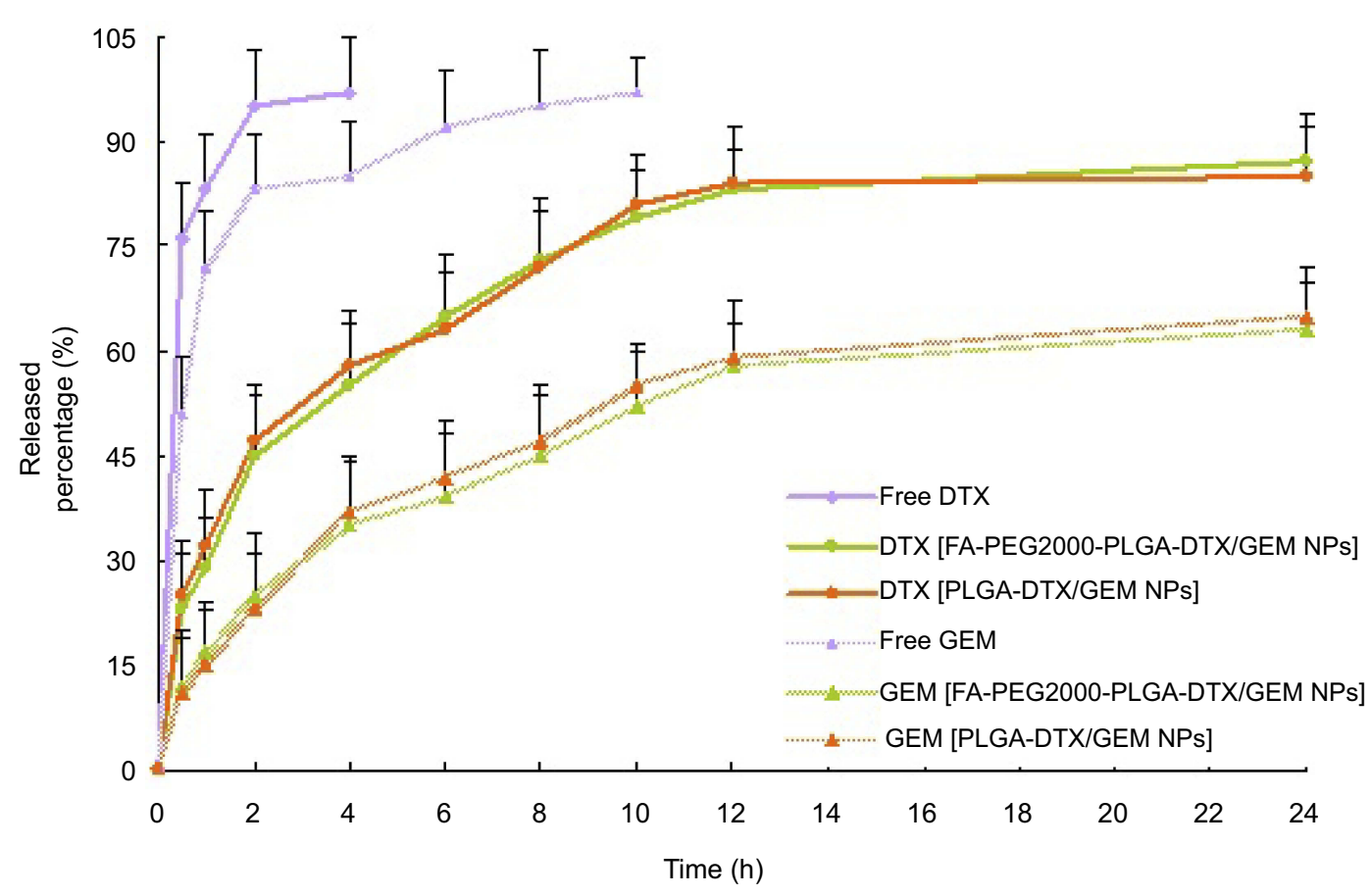

Figure 3 In vitro release profiles of DTX and GEM from different nanoparticles. Release experiments were carried out in PBS as a dissolution medium at $37 \pm 0.5 \circ \mathrm{C}$. Each point represents the mean value of three different mean $\pm S D$. $(n=3)$.

Abbreviations: DTX, docetaxel; GEM, gemcitabine; NPs, nanoparticles.

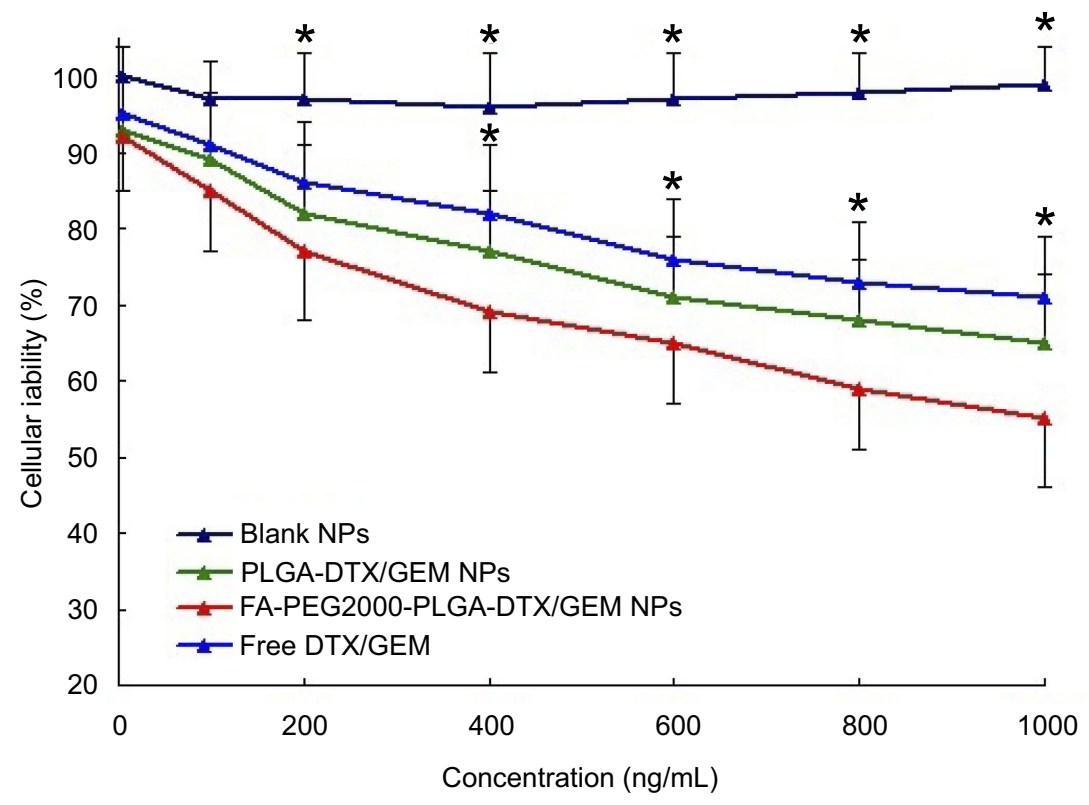

Figure 4 The cytotoxicity assay of different DTX/GEM formulations in SKOV-3 cells. *p<0.05, The other three groups vs FA-PEG $2000-P L G A-D T X / G E M ~ N P s . ~(n=6)$. Abbreviations: DTX, docetaxel; GEM, gemcitabine; NPs, nanoparticles.

drug NPs from the celland coumarin-6 in the three formulations was quantified by measuring the fluorescence. Quantitative results were consistent with the confocal images (Figure 5B).

\section{Antitumor study}

To determine the therapeutic effects of the FA-PEG2000PLGA-DTX/GEM NPs, nude mice were implanted with SKOV-3 cells and used for therapeutic efficacy evaluation 
of free DTX/GEM or DTX/GEM NPs. As shown in Figure 6, the other three groups were better able to inhibit tumor growth and decrease tumor size when compared with the control group. At the end of the experiment, tumors were found to be more sensitive to FA-PEG2000-PLGADTX/GEM NPs at a volume of $243.6 \pm 123.9 \mathrm{~mm}^{3}$, compared to that of the PBS group $\left(1237.2 \pm 276.3 \mathrm{~mm}^{3}\right)$; free DTX/GEM $\left(787.6 \pm 131.7 \mathrm{~mm}^{3}\right)$ and PLGA-DTX/GEM NPs $\left(512.5 \pm 156.1 \mathrm{~mm}^{3}\right)$. The results indicated a significant effect on the reduction rate of tumor volume for FA-PEG 2000-PLGA-DTX/GEM NPs, which was statistically higher than other groups. Because of the EPR effect and receptor ligand-mediated targeted delivery, FA-modified NPs increased accumulation of DTX/GEM in tumors and enhanced the anticancer effect in vivo (Figure 6A). ${ }^{19,20}$ Toxicity of normal organs has always been a common limiting factor in clinical use of anticancer drugs. Thus, the body weight and survival rate of mice were tested to evaluate the toxicity of NPs. There was no significant change in body weight and organ coefficient in different preparations (Figure 6B). In addition, no death occurred until the completion of this study. It was confirmed in vitro that NPs allowed sustained release of the entrapped drug, which might result in a decrease in the dose administered and in toxic side effects. H-E staining was used to determine whether there was organ damage. The results showed that
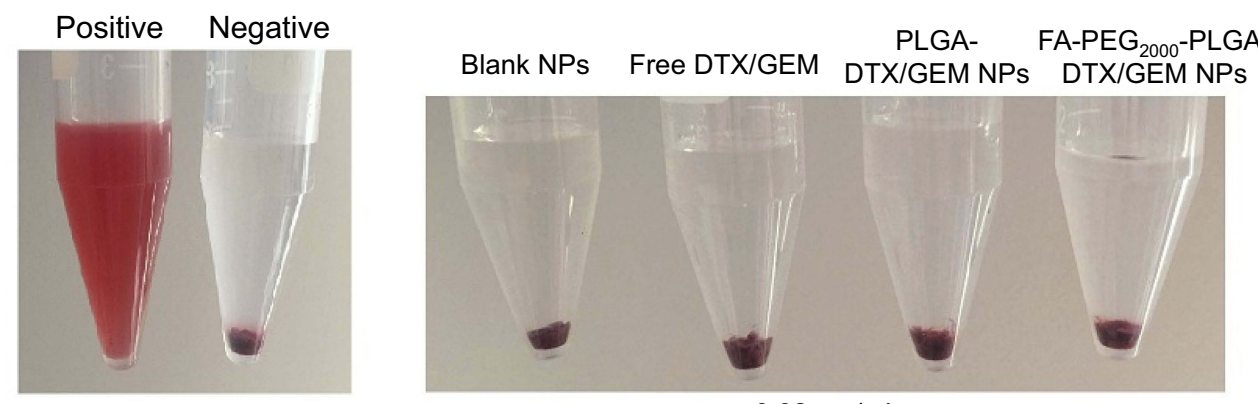

$0.02 \mathrm{mg} / \mathrm{mL}$

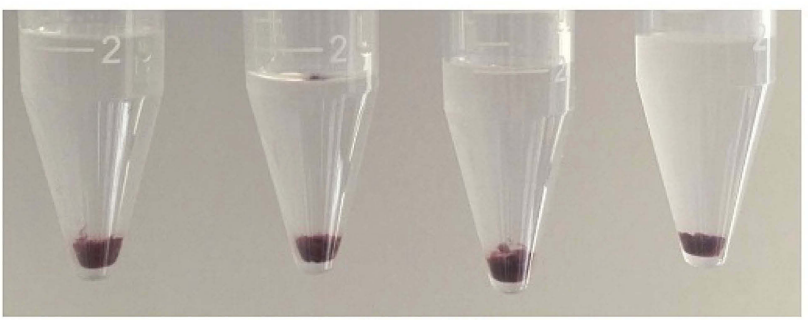

$0.15 \mathrm{mg} / \mathrm{mL}$

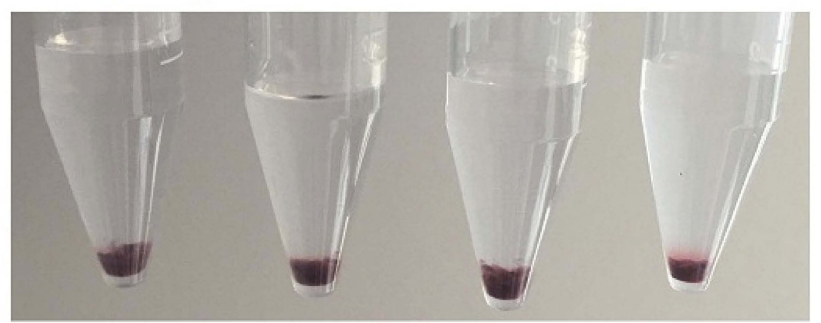

$0.05 \mathrm{mg} / \mathrm{mL}$

A

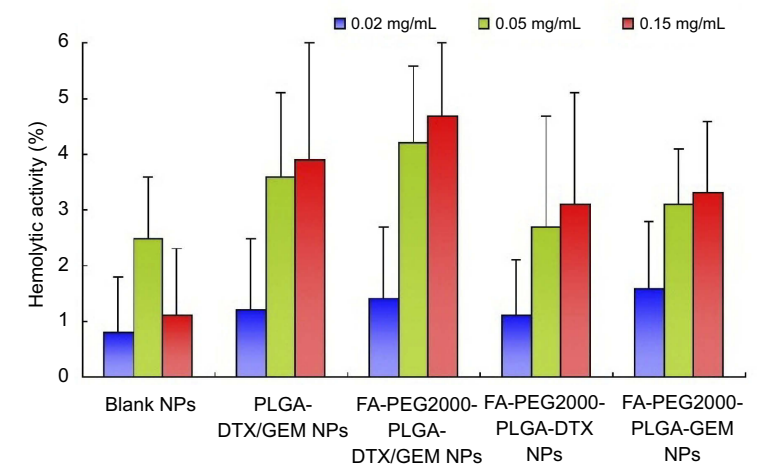

B

Figure 5 (A) Fluorescence microscope images showing the cellular uptake in SKOV-3 cells. (A) free DTX/GEM; (B) PLGA-DTX/GEM NPs; (C) FA-PEG2000-PLGA-DTX /GEM NPs. Magnification $\times 200$. (B) Mean fluorescence intensity percentage as determined by flow cytometry experiments. ${ }^{*}<<0.05$, The other three groups vs FA-PEG $2000^{-}$ PLGA-DTX/GEM NPs. $(n=6)$.

Abbreviations: DTX, docetaxel; GEM, gemcitabine; NPs, nanoparticles. 


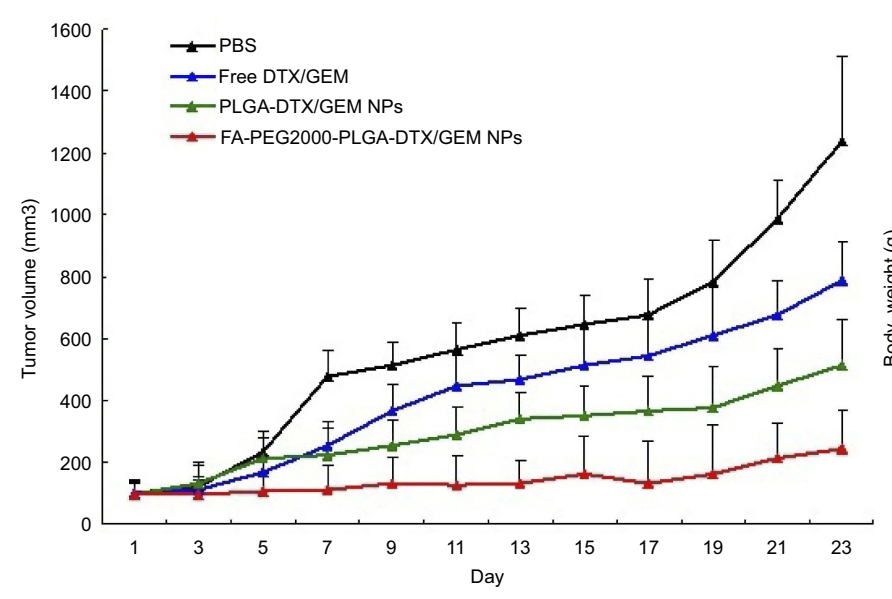

A

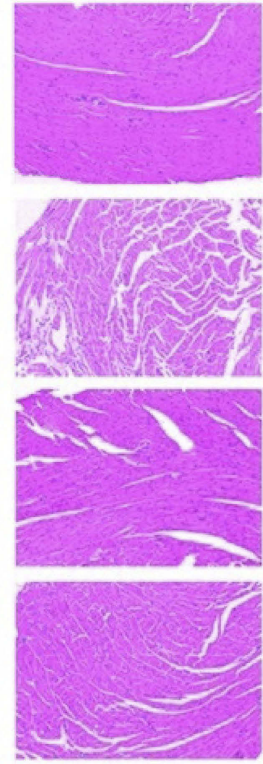

Heart
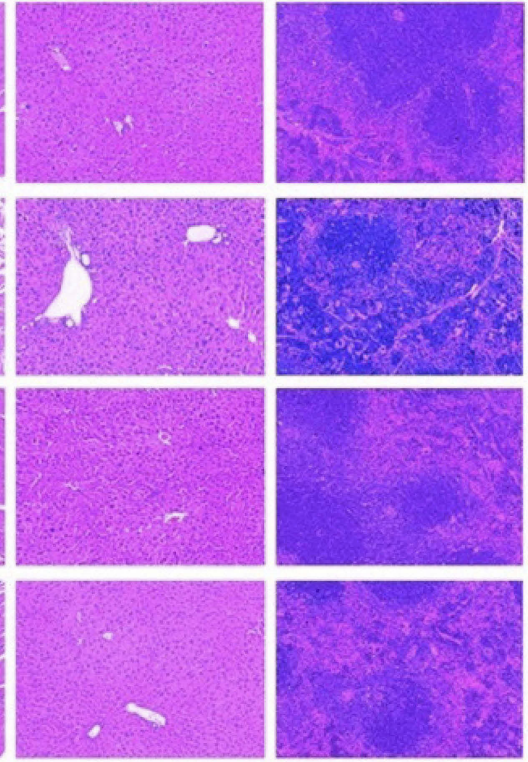

Liver

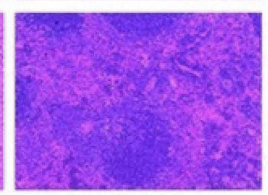

Spleen

C

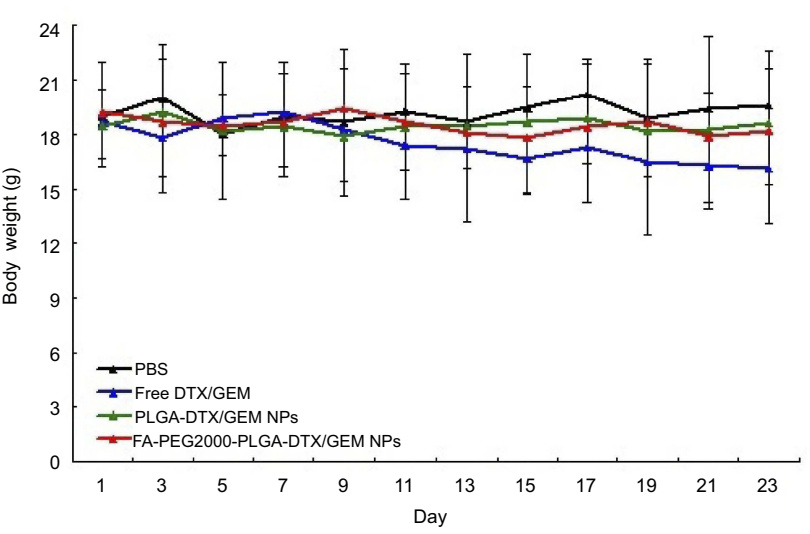

B

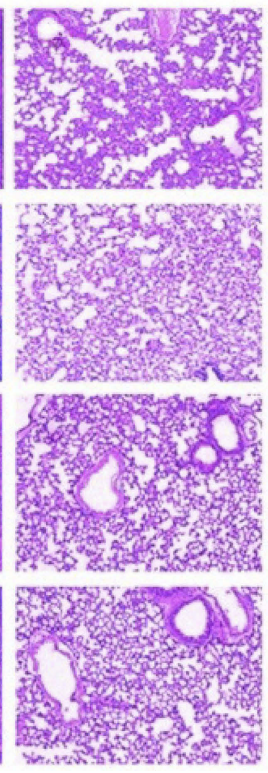

Lung

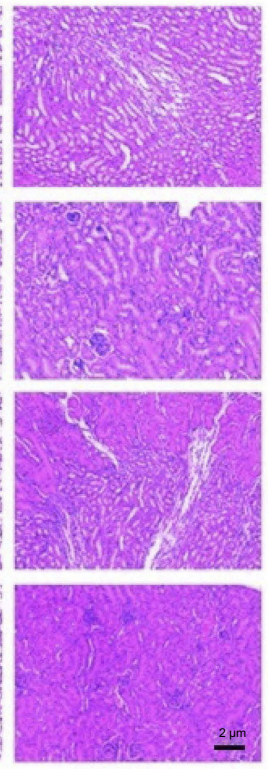

PBS

Free DTX/GEM

Kindney
FA-PEG 2000 -PLGA-

DTX/GEM NPS

PLGA-DTX/GEM NPS

Figure 6 The antitumor activity of free DTX/GEM; PLGA-DTX/GEM NPs and FA-PEG ${ }_{2000}-\mathrm{PLGA}-\mathrm{DTX} / \mathrm{GEM}$ NPs on SKOV-3 tumor-bearing nude mice. (A) Tumor volume growth curves. (B) Body weight variations of mice during the treatment. (C) Histopathological studies of heart, liver, spleen, lung and kidney. $* p<0.05$, The other three groups vs FA-PEG $2000-$ PLGA-DTX/GEM NPs. $(n=6)$

Abbreviations: DTX, docetaxel; GEM, gemcitabine; NPs, nanoparticles.

there were no obvious lesions in heart, liver, spleen, lung or kidney of the four groups, suggesting that DTX/GEM had no obvious acute toxicity in vivo (Figure 6C).

\section{Conclusion}

In this study, a novel FA-targeted co-delivery of DTX and GEM NPs was developed to overcome ovarian cancer. The hemolysis results indicated that FA-PEG ${ }_{2000}-$ PLGA was potentially feasible for targeted antitumor drug delivery through blood circulation. In vitro release study suggested that in comparison with the free drug, PLGA-DTX/GEM NPs and FA-PEG ${ }_{2000}-$ PLGA-DTX/GEM NPs had better sustained-release properties. However, there was no obvious difference between the two NPs with the same drug in the release profile. Ovarian cancer cells in vitro efficiently took up the non-targeted and FA-targeted NPs; improved cytotoxicity was observed for the FA-targeted NPs, showing a 3.59- fold drop in the $\mathrm{IC}_{50}$ in SKOV-3 cells as compared to DTX/GEM alone. Cellular uptake showed that because of surface modification, more drugs entered the cell successfully. Pharmacodynamics results showed a significant effect on the reduction rate of tumor volume for FA$\mathrm{PEG}_{2000}$-PLGA-DTX/GEM NPs, which was statistically higher than other groups, and no toxicity of organs. 


\section{Acknowledgments}

This study was funded by National Natural Science Foundation (81572546, 81372305), the project of Tongji University basic research capability enhancement (20120170047).

\section{Disclosure}

The authors report no conflicts of interest in this work.

\section{References}

1. Jemal A, Murray T, Ward E, et al. Cancer statistics. CA Cancer J Clin. 2005;55(1):10-30. doi:10.3322/canjclin.55.1.10

2. McGuire WP, Hoskins WJ, Brady MF, et al. Cyclophosphamide and cisplatin compared with paclitaxel and cisplatin in patients with stage III and stage IV ovarian cancer. $N$ Engl J Med. [comment]. 1996;334(1):1-6. doi:10.1056/NEJM199606133342404

3. Gao X, Wang S, Wang B, et al. Improving the anti-ovarian cancer activity of docetaxel with biodegradable self-assembly micelles through various evaluations. Biomaterials. 2015;53:646-658. doi:10.1016/j. biomaterials.2015.02.108

4. Beers MH, Berkow R, editors. Ovarian cancer. In: The Merck Manual of Diagnosis and Therapy. $17^{\text {th }}$ ed. Whitehouse Station, NJ: Merck Research Laboratories; 1999:1962-1964.

5. Fan R, Tong A, Li X, et al. Enhanced antitumor effects by docetaxel/ LL37-loaded thermosensitive hydrogel nanoparticles in peritoneal carcinomatosis of colorectal cancer. Int $J$ Nanomedicine. 2015;10:7291-7305. doi:10.2147/IJN.S89066

6. Ishmael DR, Hamilton SA, Launey-Rodolf RM, Nordquist J, Nordquist RE. Phase VII trial of sequential docetaxel and gemcitabine - a new schedule based on preclinical testing with the BOT-2 human breast cancer cell line. Proc Am Soc Clin Oncol. 2001;20:473.

7. Kushwah V, Katiyar SS, Agrawal AK, Gupta RC, Jain S. Co-delivery of docetaxel and gemcitabine using PEGylated self-assembled stealth nanoparticles for improved breast cancer therapy. Nanomedicine. 2018;14(5):1629-1641. pii: S1549-9634(18)30081-9.

8. Kushwah V, Katiyar SS, Dora CP, et al. Co-delivery of docetaxel and gemcitabine by anacardic acid modified self-assembled albumin nanoparticles for effective breast cancer management. Acta Biomater. 2018;73:424-436. pii: S1742-7061(18)30189-2.

9. Fan Y, Wang Q, Lin G, Shi Y, Gu Z, Ding T. Combination of using prodrug-modified cationic liposome nanocomplexes and a potentiating strategy via targeted co-delivery of gemcitabine and docetaxel for CD44-overexpressed triple negative breast cancer therapy. Acta Biomater. 2017;62:257-272. doi:10.1016/j.actbio.2017.08.034
10. O'Shannessy DJ, Yu G, Smale R, et al. Folate receptor alpha expression in lung cancer: diagnostic and prognostic significance. Oncotarget. 2012;3 (4):414 425. doi:10.18632/oncotarget.489

11. Assaraf YG, Leamon CP, Reddy JA. The folate receptor as a rational therapeutic target for personalized cancer treatment. Drug Resist Updat. 2014;17(4-6):89-95. doi:10.1016/j. drup.2014.10.002

12. Zhao XB, Lee RJ. Tumor-selective targeted delivery of genes and antisense oligodeoxyribonucleotides via the folate receptor. $A d v$ Drug Deliv Rev. 2004;56(8):1193-1204. doi:10.1016/j. addr.2004.01.005

13. Wang JQ, Mao WW, Lock LL, et al. The role of micelle size in tumor accumulation, penetration, and treatment. ACS Nano. 2015;9 (7):7195-7206. doi:10.1021/nn507282f

14. Duan XP, Li YP. Physicochemical characteristics of nanoparticles affect circulation, biodistribution, cellular internalization, and trafficking. Small. 2013;9(9-10):1521-1532. doi:10.1002/ smll.201201390

15. Wei YM, Liang J, Zheng XL, et al. Lung-targeting drug delivery system of baicalin-loaded nanoliposomes: development, biodistribution in rabbits, and pharmacodynamics in nude mice bearing orthotopic human lung cancer. Int J Nanomedicine. 2017;12:251-261. doi:10.2147/IJN.S119895

16. Hsu LL, Champion HC, Campbell-Lee SA, et al. Hemolysis in sickle cell mice causes pulmonary hypertension due to global impairment in nitric oxide bioavailability. Blood. 2007;109(7):3088-3098. doi:10.1182/blood2006-02-004234

17. Xu Z, Chen L, Gu W, et al. The performance of docetaxel-loaded solid lipid nanoparticles targeted to hepatocellular carcinoma. Biomaterials. 2009;30(2):226-232. doi:10.1016/j.biomaterials.2008.09.014

18. Noori Koopaei M, Khoshayand MR, Mostafavi SH, et al. Docetaxel loaded PEG-PLGA nanoparticles: optimized drug loading, in-vitro cytotoxicity and in-vivo antitumor effect. J Pharm Res. 2014;13 (3):819-833.

19. Pan D, She W, Guo C, Luo K, Yi Q, Gu Z. PEGylated dendritic diaminocyclohexyl-platinum (II) conjugates as $\mathrm{pH}$-responsive drug delivery vehicles with enhanced tumor accumulation and antitumor efficacy. Biomaterials. 2014;35(38):10080-10092. doi:10.1016/j. biomaterials.2014.09.006

20. Juvekar AS, Adwankar MK, Tongaonkar HB. Effect of cisplatin-based chemotherapy on emergence of cisplatin resistance, and its correlation with intracellular glutathione levels and accumulation of p53 protein in human varian cancer. Cancer Biother Radiopharm. 2000;15(3):295-300. doi:10.1089/ 108497800414392
Drug Design, Development and Therapy

\section{Publish your work in this journal}

Drug Design, Development and Therapy is an international, peerreviewed open-access journal that spans the spectrum of drug design and development through to clinical applications. Clinical outcomes, patient safety, and programs for the development and effective, safe, and sustained use of medicines are a feature of the journal, which has also been accepted for indexing on PubMed Central. The manuscript management system is completely online and includes a very quick and fair peer-review system, which is all easy to use. Visit http://www. dovepress.com/testimonials.php to read real quotes from published authors. 